\title{
Life after Trafficking in Azerbaijan: Reintegration experiences of survivors
}

\author{
Lauren A. Mc Carthy ${ }^{1}$
}

\begin{abstract}
Assisting survivors of trafficking is considered one of the pillars of a human rights-based response. Shelter, medical, psychological and legal assistance in the short term and job placement, accommodation and reunification with family and community in the long term are critical steps for helping them recover and feel in control of their lives and futures. This paper examines survivors' experiences of trafficking and recovery in the Azerbaijani context, using questionnaire responses from 22 women who were trafficked for sexual exploitation between 2006 and 2009 and who were assisted upon their return. It finds that while Azerbaijan has been quite successful at short-term assistance, there are still significant gaps in longer-term assistance, especially with regard to job placement and family reunification. Survivors point to these gaps as significant impediments to full reintegration into society. Looking at their experiences can provide insights into improvements in assistance programmes that can be implemented in both Azerbaijan and elsewhere.
\end{abstract}

Keywords: trafficking assistance, reunification, rehabilitation, reintegration, Azerbaijan

Please cite this article as: L A McCarthy, 'Life after Trafficking in Azerbaijan: Reintegration experiences of survivors', Anti-Trafficking Review, issue 10, 2018, pp. 105-122, www.antitraffickingreview.org

\section{Introduction}

In both national and international law, states have committed to assisting victims of trafficking, yet this promise has been unevenly carried out in practice. Key forms of assistance include shelter, medical, psychological and legal assistance as well as help finding jobs, permanent accommodations and reunification with family and community. Each type of assistance can play a role in helping to re-establish personal autonomy, giving survivors a chance to actively participate in shaping their post-trafficking life and future. ${ }^{2}$ However, the process of re-integration and recovery is a long one, with most trafficked persons requiring support for at least one to two years and facing many setbacks along the way. ${ }^{3}$ The physical and psychological impacts of human trafficking can continue beyond the immediate post-trafficking stage and often require ongoing treatment. Return and reintegration is also complicated by the fact that many survivors return to similar economic and familial situations that pushed them into trafficking in the first place. ${ }^{4}$

Reintegration is a deeply personal process, with each survivor experiencing it differently depending on the context of the family and the community (gender attitudes, stigma) as well as the structural conditions of the area (employment opportunities, education, service availability). This paper examines survivors' experiences of trafficking and recovery in the Azerbaijani context, using questionnaire responses of 22 women who were trafficked for sexual exploitation between 2006 and 2009 and who were assisted upon their return. This study finds that while the assistance provided to survivors was the strongest in meeting their immediate posttrafficking needs, the assistance they most desire is that which is most difficult to provide and requires the most resources. Nearly all of the 22 survivors were provided psychological, medical and legal assistance, and

1 The author would like to thank the International Organization for Migration (IOM) for permission to use this data. The opinions expressed in this article are those of the author and do not necessarily reflect the views of the IOM. Thank you also to two anonymous reviewers for their suggestions.

2 R Surtees and F de Kerchove, 'Who Funds Re/integration? Ensuring sustainable services for trafficking victims', Anti Trafficking Review, issue 3, 2014; A Lisborg and S Plambech, Going Back - Moving On: A synthesis report of the trends and experiences of returned trafficking victims in Thailand and the Philippines, International Labour Organization, Bangkok, 2009.

3 R Surtees, Re/integration of Trafficked Persons: Handling 'difficult' cases, King Baudouin Foundation (KBF), Brussels and NEXUS Institute, Vienna, 2008.

4 Lisborg and Plambech. 
temporary accommodation in a shelter. However, fewer benefitted from long-term assistance, such as help with job opportunities, permanent housing or reunification with their families.

This study is important to broaden the existing literature on trafficking assistance beyond the context of Eastern Europe, Asia and the United States. ${ }^{5}$ Though much of the trafficking experience and recovery process is similar across contexts, there are also different cultural aspects, both societal and religious, to the types of vulnerabilities and reintegration processes that exist in Azerbaijan. Here, the secular Soviet legacy combines with a post-Soviet resurgence in Islamic practices (over 95 per cent of Azerbaijan's population identifies as Muslim) and the forces of globalisation and Westernisation. ${ }^{6}$ Azerbaijani victims of trafficking must navigate a predominantly patriarchal societal context in which women, although highly educated, often have lower status than men and where economic opportunities are limited. ${ }^{7}$ Looking at their experiences can provide insight more broadly into what survivors need and the difficulties of providing it, even when the laws on the books promise generous benefits.

\section{The Azerbaijani Context}

Azerbaijan is a signatory to all major international conventions that deal with human trafficking. The government signed the UN Trafficking Protocol in 2000 and ratified it in May 2003, and in June 2010, ratified the Council of Europe Convention on Action against Trafficking in Human Beings. On paper, Azerbaijan has pursued one of the most comprehensive approaches to human trafficking in the post-Soviet region. The anti-trafficking law, signed in 2005, created a National Coordinator on Anti-Trafficking Activities, a National Referral Mechanism and a Department for the Fight against Human Trafficking in the Ministry of Internal Affairs to collate and store all information on human trafficking victims and coordinate anti-trafficking prosecutions and assistance provision. There is a National Action Plan that has been updated every three years since 2004. Since October 2007, the Ministry of Internal Affairs has operated a 24-hour toll-free national hotline for victims and potential victims of trafficking. A state-run and funded shelter was opened in $2006 ;{ }^{8}$ however, victims must be cooperating with law enforcement to receive assistance there and the criminal process must already be underway. Consequently, most women prefer to receive assistance at one of the three NGO-run shelters, including Clean World, which is where most of the women in this survey had received assistance.

The structural conditions and community context that survivors return to also has an impact on their life after trafficking. In Azerbaijan, two factors are particularly salient—gender attitudes and a lack of employment opportunities for women. According to the 2015 UNDP Human Development Report, Azerbaijan ranks the worst of the post-Soviet countries in gender inequality. ${ }^{9}$ Though a gender equality law was signed in 2006, women in Azerbaijan still occupy a subordinate position to men in the workplace and in private and public life. In 2009, The Convention on the Elimination of All Forms of Discrimination against Women (CEDAW) Review Committee noted 'deep-rooted patriarchal attitudes subordinating women and the strong stereotypes regarding their roles and responsibilities in the family and society.... and are a root cause of women's disadvantaged position in political life, the labour market, education and other areas'. ${ }^{10}$ They reached a similar conclusion in the 2015 review. ${ }^{11}$

5 On Eastern Europe, see: R Surtees, Listening to Victims: Experiences of identification, return and assistance in South-Eastern Europe, International Centre for Migration Policy Development, Vienna, 2007; R Surtees, Re/integration of Trafficked Persons: Handling 'difficult' cases; R Surtees, Re/integration of Trafficked Persons - How can our work be more effective? KBF, Brussels and NEXUS Institute, Vienna, 2008. On Asia, see: Lisborg and Plambech; R Surtees, After Trafficking: Experiences and challenges in the (re)integration of trafficked persons in the Greater Mekong Sub-region, UNIAP/NEXUS Institute, Bangkok, 2013. On the United States, see: D Brennan, Life Interrupted: Trafficking into forced labor in the United States, Duke University Press, 2014.

6 M Najfizadeh, 'Gender and Ideology: Social change and Islam in post-Soviet Azerbaijan', Third World Studies, vol. 29, issue 1, 2012, pp. 81-101.

7 United Nations Development Programme, Ažerbaijan Human Development Report 2007: Gender attitudes in Azerbaijan: Trends and challenges, UNDP Azerbaijan, Baku, 2007; F Heyat, 'Globalization and Changing Gender Norms in Azerbaijan', International Feminist Journal of Politics, vol. 8, issue 3, 2007, pp. 394-412.

8 Azerbaijan Government, Responses to the list of issues and questions with regard to the consideration of the fourth periodic report, Committee on the Elimination of Discrimination against Women, Pre-session Working Group, Forty-fourth session, 20 July-7 August 2009, CEDAW/C/AZE/Q/4/Add.1.

9 United Nations Development Programme, Human Development Report, http://hdr.undp.org/en/countries/profiles/AZE.

10 CEDAW Committee, Concluding Observations of the Committee on the Elimination of Discrimination against Women, Forty-fourth session, 20 July-7 August 2009, CEDAW/C/AZE/CO/4. 
There is a high tolerance of violence against women (by both men and women), high rates of underage marriage for women and strict attitudes towards sexual honour and purity. ${ }^{12}$

Life after trafficking can also be impacted by attitudes towards and opportunities for women in the labour market. Though the proportion of women in the labour market has increased since the $1990 \mathrm{~s},{ }^{13}$ there is still a significant gap between men's and women's wages. Traditional gender roles of the man as breadwinner and the woman as responsible for the home persist, as do beliefs that there are spheres of work that are appropriate for each gender, relegating women to lower paying jobs such as teaching or nursing. Though many Azerbaijani men migrate out of the country for work, there is significant stigma attached to a woman's decision to seek work abroad. They are viewed as abandoning their roles as wives and mothers, at high risk for their morals to be compromised, and vulnerable to exploitation, including being forced into criminal activities. ${ }^{14}$

\section{Data}

The data for this paper comprises responses of former victims of trafficking to questionnaires administered in 2011 in the context of an International Organization for Migration (IOM) report to assess the sustainability of reintegration and the risks of re-trafficking in Azerbaijan. I was the author of the (unpublished) report, but did not participate in the data gathering process. In Azerbaijan, the IOM works with the government and NGO partners to facilitate victims' return and reintegration. Respondents were 22 women who were trafficked either out of or into Azerbaijan between the years 2006 to 2009 and who met the IOM's criteria for identifying victims of trafficking. ${ }^{15}$ During that period, a total of 120 people received assistance. The ones who participated in the survey were those for whom contact information was still available. Nine had been trafficked to Turkey, five to the United Arab Emirates (Dubai) and one each to Iran and Georgia. ${ }^{16}$ There were six cases of domestic trafficking and two cases where victims were brought into Azerbaijan from Uzbekistan. Those who consented to participate were interviewed in Azerbaijani by a representative of the NGO Clean World and the interviews were translated into English. The Uzbek citizens trafficked into Azerbaijan were interviewed in Russian by an NGO in Uzbekistan. ${ }^{17}$ The surveys consisted of both open and close-ended questions focusing on survivors' personal histories, recollections of their trafficking experiences, their current situations and their plans for the future.

There are some limitations to this data. First, the respondents represent a convenience sample and are not necessarily representative of the entire population of trafficking survivors in Azerbaijan, nor the population of those assisted..$^{18}$ Studies have suggested that trafficking of men into labour exploitation is a significant problem, but there are no males in this group. ${ }^{19}$ Second, those who receive assistance may be qualitatively different from those who do not seek assistance or refuse assistance. ${ }^{20}$ Furthermore, survivors who still maintained contact with NGOs between two to five years after their trafficking situation might also be different from those with whom the NGOs lost touch. When assistance providers interview survivors, it may also skew their opinions

11 CEDAW Committee, Concluding Observations on the fifth periodic report of Azerbaijan, Sixtieth session, 16 February-6 March 2015, CEDAW/C/AZE/CO/5.

12 S Wilson, 'Majoritarian Values and Women's Rights: Police and judicial behavior in Tajikistan and Azerbaijan', Post Soviet Affairs, vol. 33, issue 4, 2017, pp. 298-312; R Rosenberg, Domestic Violence in Europe and Eurasia, USAID, Washington DC, 2006; UNICEF, Early Marriages: Violation of the human rights of children, UNICEF Azerbaijan, Baku, 2010; G Ragifgizi, 'Curbing Child Marriage in Azerbaijan', Institute for War and Peace Reporting, CRS Issue 600, 18 July 2011; G Mammadova and K Dadashova, Gender Association "Symmetry" NGO Shadow Report: Women Position in Labor Market (Article 11 of CEDAW) and Violence Against Women (General Recommendation 19), Azerbaijan, 2009; UNDP, Gender Attitudes.

13 M Sabi, 'The Impact of Economic and Political Transformation on Women: The case of Azerbaijan', Central Asian Survey, vol. 18, issue 1, 1999, pp. 111-120.

14 UNDP, Gender Attitudes.

15 See: The IOM Handbook on Direct Assistance for Victims of Trafficking, International Organization for Migration, Geneva, 2007.

16 Two respondents had been trafficked to multiple countries.

17 All survey responses were anonymised before they were given to the author for analysis.

18 On the difficulty of obtaining a representative sample of trafficking survivors for study, see: R Surtees and S Craggs, Beneath the Surface: Methodological issues in research and data collection with assisted trafficking victims, International Organization for Migration, Geneva, 2010.

19 US Department of State, 2017 Trafficking in Persons Report, Washington DC.

20 A Brunovskis and R Surtees, Leaving the Past Behind? When victims of trafficking decline assistance, Fafo, Oslo, 2007. 
towards the positive, feeling some obligation to those who have helped them. Finally, there was no opportunity for follow-up after the initial interviews were conducted to update the study to the present day, so it is possible that some circumstances may have changed. Drawing generalisable statements about any group of survivors is difficult. That said, research that focuses on survivors' voices allows us to hear what is working and what is not and to use that information to develop recommendations for improved assistance programmes. It can also complement the sorts of quantitative data that many assistance organisations and governments present (number of people assisted, types of assistance received, etc.) to give a fuller picture of life after trafficking.

\section{Victim Assistance}

The survey asked the women to specify the types of assistance that they had received after their return to their home countries:

\begin{tabular}{|l|c|}
\hline Type of assistance & Number of victims receiving ${ }^{\mathbf{2 1}}$ \\
\hline Personal safety & 6 \\
\hline Psychological counselling & 13 \\
\hline Shelter & 11 \\
\hline Medical2 & 10 \\
\hline Legal consultation & 13 \\
\hline Return home & 2 \\
\hline Meeting at airport & 3 \\
\hline Job placement & 8 \\
\hline Job counselling & 3 \\
\hline Other & 8 \\
\hline
\end{tabular}

Other types of assistance included helping them return to and reconcile with their families and helping them manage problems with their children, including finding schools. One received assistance in getting released from prison, where she was being held for theft, which her trafficker had forced her to commit.

\section{Short-Term Assistance}

Physical and mental health

Most trafficking victims experience physical and sexual violence, making medical and psychological assistance critical at both the immediate post-trafficking stage as well as at later stages of recovery. ${ }^{23}$ Longer duration in trafficking and increased severity of injuries and sexual violence sustained during trafficking have been associated with worse mental health outcomes, independent of pre-trafficking experiences of physical or sexual violence. ${ }^{24}$ In the study population, ten survivors said they had received medical assistance. Two who had returned pregnant specified that the assistance organisations had helped them to give birth. Another who returned addicted to drugs received treatment for her addiction. Thirteen of the survivors reported receiving psychological assistance, which seems to have been quite effective. When asked to be more specific about how the assistance they received has helped them, many of the answers focused on the power of the psychological aid to help them feel better about themselves and their lives and see potential for the future. In their own words: 'Psychological aid was vital for me. It helped me to recover after all the depressive things that happened to me.' 'Though it was so hard for me, I learned to believe in myself and to continue to live.'

21 Most survivors received several types of assistance. One did not receive assistance, one did not specify the type.

22 It is unclear from the surveys what type of medical assistance was provided.

23 C Zimmerman, Stolen Smiles: The physical and psychological health consequences of women and adolescents trafficked in Europe, The London School of Hygiene \& Tropical Medicine, London, 2006; M Farley (ed.), Prostitution, Trafficking, and Traumatic Stress, Routledge, New York, 2004; A Tsutsumi et al., 'Mental Health of Female Survivors of Human Trafficking in Nepal', Social Science \& Medicine, vol. 66, 2008, pp. 1841-7.

24 M Hossain et al., 'The Relationship of Trauma to Mental Disorders among Trafficked and Sexually Exploited Girls and Women', American Journal of Public Health, vol. 100, issue 12, 2010, pp. 2442-9; N Ostrovschi et al., 'Women in PostTrafficking Services in Moldova: Diagnostic interviews over two time periods to assess returning women's mental health', BMC Public Health, vol. 11, 2010, p. 232. 


\section{Accommodation and physical security}

In the immediate post-trafficking situation, victims require physical safety both for a sense of security and to protect them from their traffickers. This can take place in a shelter or by helping arrange the victim's return and/or meeting her at the airport so that she is not intercepted by her traffickers. ${ }^{25} \mathrm{~A}$ large number of them noted that the Ministry of Internal Affairs' Department on Human Trafficking had helped them and/or referred them to places where they could access assistance. Nine survivors, almost half the study population, had dealt with the department. This indicates that having a dedicated branch of the police can be an important way to assist trafficking victims if the officers are trained in dealing sensitively with victims and focus on fulfilling their mandate.

Women who do not have adequate options for shelter can become vulnerable to re-trafficking. In the immediate post-trafficking stage, housing assistance is usually provided by shelters and eleven of the survivors in the study reported having been at one. In Azerbaijan, the main NGO shelter, Clean World, and the Ministry of Internal Affairs' shelter are both in the capital city, Baku, which means that survivors are often living apart from their families when they first return. Many women are reluctant to stay in shelters far from home, especially if there are no provisions for their dependents. ${ }^{26}$

\section{Long-Term Assistance}

\section{Housing}

At best, shelters can provide a temporary living situation, which according to Azerbaijan's law is 30 days. ${ }^{27}$ Stays at NGO shelters vary and are largely dependent on funding. A permanent living situation can help survivors feel rooted in their communities, secure in their future and eliminate worry about the disruptive effects of frequent moves. The post-trafficking living situations of the interviewees varied. Most were living with their own families and children or with relatives (13/22). Three were living alone in apartments, two at the shelter, two with friends, one rented a room from an elderly woman and one lived with a romantic partner. The women who chose to go back to live with their relatives all described it as a difficult process, often requiring intensive reconciliation efforts.

\section{Economic security}

Economic empowerment and long-term or permanent employment opportunities are critical for survivors to be able to successfully reintegrate into society. A steady job with sufficient income to support the survivor and/or her dependents can ameliorate the need to migrate abroad unsafely. However, there are a number of difficulties associated with this form of assistance. Returning survivors want to start earning money right away to support themselves. Family may also pressure them to earn money quickly, especially if the trafficking was the result of failed economic migration and the family was expecting support. ${ }^{28}$ However, the trauma experienced by trafficking victims can create difficulties in concentration and low self-esteem, making it unlikely that they will be able to hold down a job immediately. ${ }^{29}$ Of the survey respondents, eight of the women received job placement assistance and three received job counselling. Four mentioned that they had enrolled in courses to increase their qualifications or to learn new skills, such as English or computer literacy.

The women in the survey have had varying levels of success in finding steady jobs. Of the 22 , only nine reported a full-time remunerated position while nine others reported having no paying job. Two had part-time work and two had occasional work. Looking more closely at these answers shows that of the women who answered that they did not currently have paying jobs, four had chosen to stay at home to raise their children and four work in the sex trade. Those who do sex work appear not to consider their work a 'paying job' insofar as the money that they bring in varies or because they only work occasionally. The remaining survivor who said she did not have a paying job was still living at the shelter. Of the two women who have occasional paying jobs,

25 A Jobe, The Causes and Consequences of Re-trafficking: Evidence from the IOM Human Trafficking Database, 2010, IOM, Geneva.

26 R Surtees, Re/integration of Trafficked Persons: Handling 'difficult' cases.

27 Law of the Republic of Azerbaijan on Trafficking in Persons (2005).

28 A Brunovskis and R Surtees, 'Coming Home: Challenges in family reintegration for trafficked women', Qualitative Social Work, vol. 12, issue 4, 2012, pp. 454-472.

$29 \mathrm{~S}$ Warnath, Examining the Intersection between Trafficking in Persons and Domestic Violence, USAID, Washington DC, 2007. 
one works in the sex trade and the other works in agriculture on her own plot of land, where she says that sometimes the harvest is not sufficient.

Despite this seeming insecurity, the women's perceptions of their current material situation-feeling that they are able to make do with what they have-was generally positive. Nine of the respondents said they made enough to cover their expenses, while nine said 'sometimes yes, sometimes no', although in the open-ended portion of this question, most tended towards yes. Four either said no or did not answer. This group of survivors, then, has been fairly successful in accomplishing one of the most difficult tasks of reintegration, movement into a stable economic situation. However, because there was no question that asked the women to specify what jobs they currently held, it is hard to say to what extent they have found careers and full-time employment that will provide for their long-term needs rather than temporary work.

Three of the full or part-time job holders have found work in the NGO sector with anti-trafficking NGOs. This seems to be a double-edged sword. On the one hand, having survivors work in NGOs makes incoming victims feel that they can identify with people who are trying to help them and can give survivors the feeling that something positive has come out of their experiences. On the other hand, there are a finite number of paying jobs in the NGO sector, so it cannot be a longer-term strategy for job placement for all returning survivors. It may also create false expectations among survivors who are receiving help that they may have a job waiting there when they finish their assistance programme

\section{Family/Social relationships}

The process of helping survivors reconcile with their families requires a careful approach. For many of the women in this study, family reconciliation was cited as evidence of successful reintegration or as part of their plans for the future to ensure that their reintegration was successful. One survivor noted the importance of the assistance organisation in facilitating the reconciliation. 'I began to work and [the NGO] helped me to meet with my family. I have reconciled with them and now I live [with] my family.'

Reintegration into the family can increase the likelihood that the return process will be sustainable, because ideally, the family will act as a mediating factor between the survivor and the community. However, it may also be fraught with difficulties including stigma, dealing with the family situation that pushed them into trafficking in the first place, or direct family involvement in the trafficking situation. ${ }^{30}$ For many of the survivors in this study, conflicts with their families over sexual honour, including lost virginity, pre-marital sex (consensual or not), co-habitation and divorce led to rejection by their parents and/or in-laws and were proximate causes for trafficking. Sixteen of the 22 women reported being trafficked by family, neighbours or close friends, the very people out of whom a post-trafficking support network might be formed.

In Azerbaijan, the stigma attached to sex work is also strong, which presents a significant challenge for survivors. ${ }^{31}$ This is more likely in rural areas where people are intimately acquainted with each other's lives and activities. On the other hand, integration into a new community also has drawbacks because the survivor has to build her support networks from scratch. ${ }^{32}$ Unfortunately, while assistance organisations can help facilitate family reconciliation, there is little they can do to educate the community and remove stigma. In patriarchal societies like Azerbaijan where women's sexual honour and purity is prized, the survivor's father and brothers may react with disgust and shame at her experience, rather than with empathy, although some of the women noted that these attitudes were mitigated by their ability to support the family financially. Another option for survivors is to hide or only partially reveal what happened to them, which may cause more stress and lack of understanding. ${ }^{33}$

For many women in this study, marriage and children were considered extremely important as indicators of their reintegration. In this group, many of the women were either single or divorced when the survey was conducted $(18 / 22)$. Three were married and one was cohabiting with her partner. Half of the women had at

30 R Surtees, Re/integration of Trafficked Persons: Handling 'difficult' cases; Warnath, Examining the Intersection; Brunovskis and Surtees, 'Coming Home'.

31 UNDP, Gender Attitudes, in the focus groups that the UNDP conducted some male and female participants went so far as to suggest death or burning for women who engaged in prostitution, p. 73.

32 Surtees, Re/integration of Trafficked Persons: Handling 'difficult' cases.

33 Brunovskis and Surtees, 'Coming Home'. 
least one child. Many credit their marriages and/or children as a stabilising factor that helped them to reintegrate into society and reconcile with their families. For those who had gotten married and/or had children, their future goals were oriented around providing for and protecting their families. On the other hand, providing for children was also a major source of concern for many of the women. Those who were unmarried or divorced view marriage as something that is important for their future plans, though, as one survivor put it, 'I would like to marry, but I know that is not easy for people like me.' Another saw marriage as the solution for having her family accept her, especially since she had been divorced previously. In their post-trafficking worlds, marriage and children seemed to allow these women to be accepted by their families in a way that careers, housing and money could not.

\section{Overall Assessment of Assistance and Plans for the Future}

All but one survivor believed that the assistance they received had helped them. ${ }^{34}$ According to one, 'now I know that I will never do prostitution and my life will be different'. According to another: 'I went to the office against human trafficking and they sent me to [the NGO]. There I was provided with shelter, legal, psychological aid. They talked with my family and especially my mother and brother...I returned to my family, I began to work, I took a course and learned a new profession. I began to believe in people again.'

Thirteen of the 22 survivors said that they felt very well integrated into society. In addition to marriage and children, they cited the fact that they held jobs, had friends and/or had reunited with their families as evidence that they have successfully rejoined their communities. Others mentioned jobs and no longer feeling ashamed as evidence that they had reintegrated. The four who felt that they were 'not so well' integrated cited continued financial concerns, psychological difficulties and the fact that they had not yet returned to their families. According to one, 'I do have enough information about my rights, in this way, yes, I'm integrated, but on the other hand I have financial problems, difficulties, in this way I'm not.' One survivor reported not feeling integrated at all and four did not answer.

In assessing their current situation on a five-point scale, ${ }^{35}$ most $(18 / 22)$ of the women said their situation was good or very good. In a separate question, nearly all said that they were better off now than they were prior to being trafficked. Three survivors said that their situation was the same and one said it was worse. The same person who assessed her current situation as very bad said her situation was worse than before. She had been trafficked into Azerbaijan for prostitution from Uzbekistan and upon her return was severely stigmatised by her family and community. She continued to work in the sex trade. The three survivors that rated their lives as the same when compared to their pre-trafficking situation all continue to make their living as sex workers. As one noted, 'the only difference is that I'm currently in the sex business willingly'. Only one other remains in sex work, but she assesses her life as better now than before because 'I earn money and like my job...actually, I don't care what people think, I just live my life as I want'.

Of those who assessed their lives as better now than before, five emphasised the fact that they were no longer afraid or ashamed. As one said, 'When I was going somewhere I thought that everyone knew that I was a prostitute.... But now I don't fear. I feel safety and self-confidence.' Others emphasised that finding work and a career had made them feel better. To all but one of these survivors (who was still working in the sex trade), work meant having a job other than sex work, the respect of those around them and the ability to support themselves and their families, either immediate or extended.

A focus on the future can be an important sign of reintegration and fifteen women said that they had concrete future plans. Two did not, four were unsure and one did not answer. When given the option to specify, answers were mainly focused on family (marriage and children), housing and jobs/careers. One survivor's statement reflects a common sentiment amongst them, 'I just want my family to be strong and want to bring up my children safely.' The desire to find something concrete that ensures their stability and ties them to their community was overwhelming. Eight mentioned getting married and/or having children, four mentioned buying land or an apartment and six mentioned developing their careers. Only one mentioned education. Some

34 The one woman who said that she did not find the assistance useful noted that she was not interested in the courses that she had gone through; she 'preferred to work in the sex business'.

35 Response options were: very good, good, reasonable, bad, very bad. 
women were optimistic about their futures. In their own words: 'Now I work. I feel safety and I believe that beautiful years wait for me.' 'I had a lot of concerns and fears about my future, but now I believe in myself and I have future plans. I will graduate from the university next year and will have a very good career.' But, for some, the trafficking situation had left them disillusioned with the world. According to one, '[I now know] there are a lot of bad and very unworthy persons.' According to another, 'I know that we cannot trust everyone.'

Most of the survivors believed that they were more protected now than when they were trafficked and credited this to the assistance they received. Among the reasons they cited: knowing who to go to for help; having information about trafficking; feeling protected, both by their families and by the organisations; and being more mature. One survivor said she learnt that 'living abroad doesn't always mean living happy'. Several also credited the aid for enabling them to resist a situation like this in the future. One of them said, 'If then I were like I am today, I'm sure that wouldn't happen to me. But now I'm well aware and I know that now I'm strong enough.' Another stated, 'I know how to react in a case like this. I know how to check whether the suggestion is false or not.' All but one knew where to go if they needed help in the future.

\section{Unmet Needs and Continuing Vulnerabilities}

About half of the survivors noted that there was assistance they wanted but did not get. However, when asked to specify, most of them focused on institutional failings of the state or their family's inability or unwillingness to help them. Four of the women described how they went to the police, two to report rape and one to report threats, and the police did nothing to help them. ${ }^{36}$ In one story, a police officer actually raped the victim when she appealed to him for help because she was running away from her sexually abusive father. Another noted that the police had made her situation much worse by telling her family what had happened, causing stigmatisation and making it impossible to return to her neighbourhood.

When asked to specify what types of assistance they still needed, much of it was focused on long-term goals: gaining acceptance from relatives, finding a place to live, getting jobs and careers in order and continued psychological aid. This indicates that the long-term needs of survivors are those which are still being unmet by assistance organisations. Ongoing job/career and psychological support, and help accessing affordable housing and other social services is something that the government assistance centres and NGOs should focus on providing to help with longer-term reintegration success.

Despite their generally positive outlooks and positive experience with assistance organisations, seven of them said that they plan to or might consider going abroad to the Middle East in the future, either for sex work or another job. Thus, it seems that even those who had plans to establish a life in Azerbaijan were still uncertain enough about those plans working out that they were ready to consider going abroad to work again. The women who planned to go abroad to work in the sex trade believed that if they were to go, they would make wiser choices. When asked how they would find the job abroad, they answered that they now know how to protect themselves and that they still had lists of their clients' phone numbers so they could call them when they arrived to start working independently. Others were less confident that they were protected from future exploitation. One survivor said that she 'liked risks and a dangerous life' but was still an 'easy believer' and another continued to worry that the police would harass or arrest her either while she was working or, if she lost support of the women who worked under her, for forcing others into prostitution.

\section{Conclusion and Lessons Learnt}

The results of this study largely confirm the findings of other studies on the importance of multiple types of post-trafficking assistance for both short and long-term needs. The fact that most of the survivors in this study felt that they were in better, more secure situations now than when they were trafficked is certainly

36 The fourth woman said that she had gone to the police many times and they did not help, but did not specify what she had approached the police about. Difficulties with police on issues of domestic violence and rape are unfortunately the norm rather than the exception, with most police reluctant to interfere in what they see as a private sphere issue, see Wilson. 
praiseworthy. They largely attribute these feelings to the assistance they received and the organisations that provided it, indicating that government and non-government organisations in Azerbaijan are having a positive impact on survivors in the immediate post-trafficking stage.

While this short-term aid is an important start on the road to reintegration, for survivors, the later stages are even more challenging. In Azerbaijan, as elsewhere, they struggle to make peace and reconcile with their families. Survivors also want to develop job and career prospects, another activity that can take time, and may require education and training to give them skills that they can apply in the job market. Survivors point to housing as another need that arises as they exit the immediate post-trafficking situation and the shelter. Many need an interim location to stay until either they have reunified with their families or they are able to make enough money to support themselves. This need is even more acute since many women have children and are not married (or are divorced). These needs are compounded by a traditional and patriarchal societal context that sees women who have engaged in prostitution as impure, unworthy and a stain on the family's honour. Structural economic factors and social factors also combine to create a labour market that gives men more and better opportunities than women.

These surveys add to existing findings in other contexts which argue that the long-term needs of human trafficking survivors remain unmet and require attention. ${ }^{37}$ Assistance organisations would do well to establish longer-term follow-up mechanisms and programmes for those who desire to access them, and donors and governments should ensure funding for them. In doing so, careful attention must be paid to the fact that many survivors may find follow-up care intrusive. As they reintegrate successfully into society, phone calls or visits by the monitoring organisation may be a continual reminder of their past and create the risk of further stigmatisation if the visits/calls occur in the presence of people unaware of the survivor's past. That said, the fact that the women in this survey were trafficked between two and five years before the interviews were conducted suggests that longer-term follow-up is possible. Many noted that they felt more secure and protected knowing services were available, even if they did not utilise them.

Another area where assistance organisations could focus for long-term needs is employment. Job counselling services that are available on an as-needed basis could provide similar support and security to survivors. Another option is to prioritise employment of trafficking survivors in the locally based victim assistance centres and in the NGO sector more broadly. This study and others have shown that survivors are often successfully employed in victim assistance organisations, where they can use their experiences to help others. ${ }^{38}$ However, since there are limited jobs available in these centres, other employment options need to exist. For those who plan to go abroad again, assistance organisations and the government should do more to facilitate and support safe migration opportunities.

In sum, the challenges of life after trafficking in Azerbaijan mirror the challenges faced by trafficking survivors around the world, especially those in countries with high levels of gender inequality and uneven levels of economic development. Focusing on survivors' experiences can be instructive in thinking through what assistance organisations and governments can do, but also in understanding their limitations. Survivors need both short and long-term assistance to have an empowered life after trafficking and organisations need resources to provide these services. However, while funding can ensure job training and housing to help women in the long term, it can do very little to mend families, change societal perceptions or to fight against the global economic trends that enable trafficking and exploitation in the first place.

\section{Post-Survey Developments}

Since the data for this survey was collected, Azerbaijan has continued to develop its legislative and policy framework surrounding human trafficking. It has also passed several laws dealing with some of the issues that make women particularly vulnerable to trafficking and struggle on their return, including a law on domestic violence and a law raising the minimum age of marriage to 18 for both men and women. There are now two government and three NGO shelters that can take human trafficking victims, all but one located in Baku.

37 See, inter alia: Brennan; Surtees and de Kerchove; Lisborg and Plambech.

38 USAID, The Rehabilitation of Victims of Trafficking in Group Residential Facilities in Foreign Countries, USAID, Washington DC, 2007. 
Victims who are officially identified as such by law enforcement are eligible for a one-time lump sum of AZN 400 (USD 235 or EUR 200) and most appear to be receiving this payment. Though there is also a state victim assistance fund, so far it has been financed primarily by private donors, an indication that it is still a challenge for the state to provide ongoing assistance for survivors. ${ }^{39}$

There is still more focus on immediate post-trafficking needs, but there seems to be an increase in attention to longer-term assistance. Survivors can be referred to a state-run assistance centre specifically focused on trafficking victims, which offers jobs and vocational training in partnership with the Ministry of Labour along with medical, psychological and legal assistance. Funding for trafficking related projects and for victim assistance has increased, though the recent assessments by the Group of Experts on Action against Trafficking in Human Beings (GRETA) and CEDAW review committees suggest that state-run institutions are still significantly under-resourced and rely heavily on money from international organisations. ${ }^{40}$ In its most recent response to the GRETA review committee, the Azerbaijani government reported that it had assisted 63 victims in the previous year. Fifty-one were sheltered at the state-run shelter and received assistance there, 31 were enrolled in vocational courses and 22 found employment. Almost all received the payment of AZN 400. ${ }^{41}$ These numbers are encouraging. However, additional qualitative work is needed to help contextualise what they mean. Have women found permanent jobs with living wages to support themselves and their children? Have they been able to establish a life that no longer feels precarious or do they still feel economically and socially vulnerable?

Lauren A. McCarthy is Associate Professor of Political Science and Legal Studies at University of Massachusetts Amherst. Her research focuses on human trafficking and policing in Russia and the former Soviet Union. McCarthy is the author of Trafficking Justice: How Russian police enforce new laws, from crime to courtroom (Cornell, 2015) and numerous other publications on human trafficking. Email: mccarthy@legal.umass.edu

39 Group of Experts on Action against Trafficking in Human Beings, Report concerning the implementation of the Council of Europe Convention on Action against Trafficking in Human Beings by Azerbaijan, Strasbourg, 2014.

40 GRETA; CEDAW 2015

41 Report submitted by the authorities of Azerbaijan on measures taken to comply with Committee of the Parties Recommendation CP(2014)10 on the implementation of the Council of Europe Convention on Action against Trafficking in Human Beings, 2016. 